\title{
A simple parameterization for tsunami run-up prediction
}

\author{
Latifatul Cholifah ${ }^{1,2}$, Tjipto Prastowo ${ }^{1,2^{*}}$ \\ ${ }^{1}$ Physics Department, FMIPA, Universitas Negeri Surabaya, \\ Kampus Unesa Ketintang, Surabaya 60231, Indonesia \\ ${ }^{2}$ Research Center for Earth Science Studies, Physics Department, \\ Kampus Unesa Ketintang, Surabaya 60231, Indonesia
}

\begin{abstract}
The linear shallow-water approximation is commonly used to describe tsunami propagation, where the wave is assumed as a long surface gravity wave. The evolution of wave height during its propagation from offshore to onshore is a classic problem. When arriving at a shoreline, the increased wave height causes severe destruction on infrastructures and fatalities. This problem has then been an important issue within the context of disaster risk reduction as it gives rise to the importance of tsunami run-up prediction. Using maximum run-up data from past events, we tested the applicability of the Green's law based on shoaling only to calculate run-ups and found that the basic Green's law was in doubt. Then, we examined energy density conservation involving refraction effect but no dissipation and derived a simple formula for parameterizing run-up height. Detailed descriptions on factors affecting run-ups, such as complex bathymetry and topography are not yet considered in the current study. The aim of this study is therefore to determine whether the modified Green's law is applicable for tsunami run-up prediction using local water depths as external parameters and ray spacing widths in the normal direction of wave fronts related to refraction. The results are consistent with the measured run-ups, where approximately $70 \%$ of total points of observations confirm the modified Green's law with a reasonable accuracy.
\end{abstract}

Keywords: Green's law, refraction effect, shoaling, tsunami run-up prediction

Received: July 20, 2017; Accepted: September 8, 2017; Published online: October 24, 2017

*Corresponding author: tjiptoprastowo@unesa.ac.id

Citation: Cholifah, L., \& Prastowo, T. (2017). A simple parameterization for tsunami run-up prediction. Journal of Science and Science Education, 1(1), 7-13.

\section{Introduction}

The linear shallow-water approximation, regardless of wave shape (Choi et al., 2011), is commonly used to describe tsunami wave propagation in the open oceans. In many literatures, the wave is assumed as a long surface gravity wave, where time evolution of the wave amplitude during its propagation from a tsunami source location offshore to places nearby a beach onshore is a classic problem in physics of oceanic water waves (Synolakis, 1991). It has been widely known that the group velocity of the long wave, transporting tsunami energy, changes with water depth and slows down when it approaches a shoreline. In turn, a decrease in the transport velocity must be compensated by an increase in the wave amplitude and hence the wave height inland, possibly causing severe damage on local structures and losses of human lives. This problem has therefore been an important issue in the context of disaster risk reduction as it gives rise to the importance of tsunami run-up prediction (Mori et al., 2011; Reymond et al., 2012; Goto et al., 2013). 
Tsunami run-up, or more precisely tsunami run-up height, is here defined as the height of the furthest point of inundation distance inland measured from the mean seawater surface level. The run-up data records may thus be used as an effective indicator of local impacts of the event on coastal regions (Charvet et al., 2013), prompting the necessity of quick and accurate prediction of run-up heights for tsunami early warning (Chen et al., 2012; Lin et al., 2014). In line with this need, the present work in part focuses on providing physical grounds on the problem in question where conservation of energy density flux, neglecting energy dissipation due to seabed friction and other mechanisms (WMO, 1998; Hayashi, 2010; Fuchs, 2013), is then used to derive a simple formula for tsunami run-up parameterization.

Detailed descriptions on factors influencing run-up heights, such as complex bathymetry and the bottom slope of local topography go beyond of the current study. The aim of this study is therefore to test and determine the applicability of the Green's law for tsunami run-up estimates using water depths as local parameters and orthogonal spacing widths of two adjacent refracted wave rays in the normal direction of wave fronts. In short, we include effect of wave refraction with no loss of energy in the basic Green's law for run-up prediction and then examine how close the results derived from the modified Green's law compared to run-ups obtained from simulations (Hirata et al., 2004; Lin et al., 2014) and field surveys (Goto et al., 2013).

\section{Methods}

A combined set of basic physics principles are used to govern the dynamic equations, on the basis of linear shallow-water wave approximation, describing tsunami long-wave propagation in the ocean. These include momentum and continuity equations, hydrostatic pressure balance and mechanical work required for transfer of energy between kinetic energy and potential energy that lead to the conservation of tsunami energy density flux during tsunami wave propagation. We leave the full details of mathematical derivation at this stage and instead directly write here the tsunami energy density conservation as follows,

$$
\frac{d}{d x}\left(c_{g} \varepsilon\right)=0
$$

where $c_{g}=\sqrt{g d}$ is the group velocity of a tsunami wave with $d$ is the local water depth, $g$ is acceleration due to gravity, and $\varepsilon=\frac{1}{2} \rho g a^{2}$ is the energy density with $\rho$ is the density of seawater and $a$ is the wave amplitude. In Eq. (1), the $x$-axis is the direction of tsunami propagation.

Using Eq. (1), we derive the famous Green's shoaling law relying only upon knowledge of local water depths obtained from offshore and onshore observations for predicting maximum run-up heights at places onshore as follows,

$$
R_{\mathrm{est}}=\left(\frac{D}{d}\right)^{\frac{1}{4}} \eta
$$

where $R_{\text {est }}$ is the maximum run-up height, $D$ and $d$ are the offshore and onshore water depths, respectively, and $\eta$ is the vertical displacement of the sea surface at offshore. Eq. (2) thus simply relates field data from offshore observatories to those from coastal stations and is used to predict to first order the run-up heights at some specific locations due to three large tsunamis induced by undersea earthquakes in the Japanese east coast: the 2011 Tohoku event of magnitude $M_{\mathrm{w}}=8.9$ with the epicenter at $38.3^{\circ} \mathrm{N}$ and $142.4^{\circ} \mathrm{E}$ and the 2003 Tokachi tsunami of magnitude $M_{\mathrm{W}}=8.0$ with the epicenter at $41.8^{\circ} \mathrm{N}$ and $144.1^{\circ} \mathrm{E}$, and in the Sumatra west coast: the 2004 Indian Ocean tsunami of magnitude $M_{\mathrm{w}}=9.1$ with the epicenter at $3.4^{\circ} \mathrm{N}$ and $95.7^{\circ} \mathrm{E}$. 


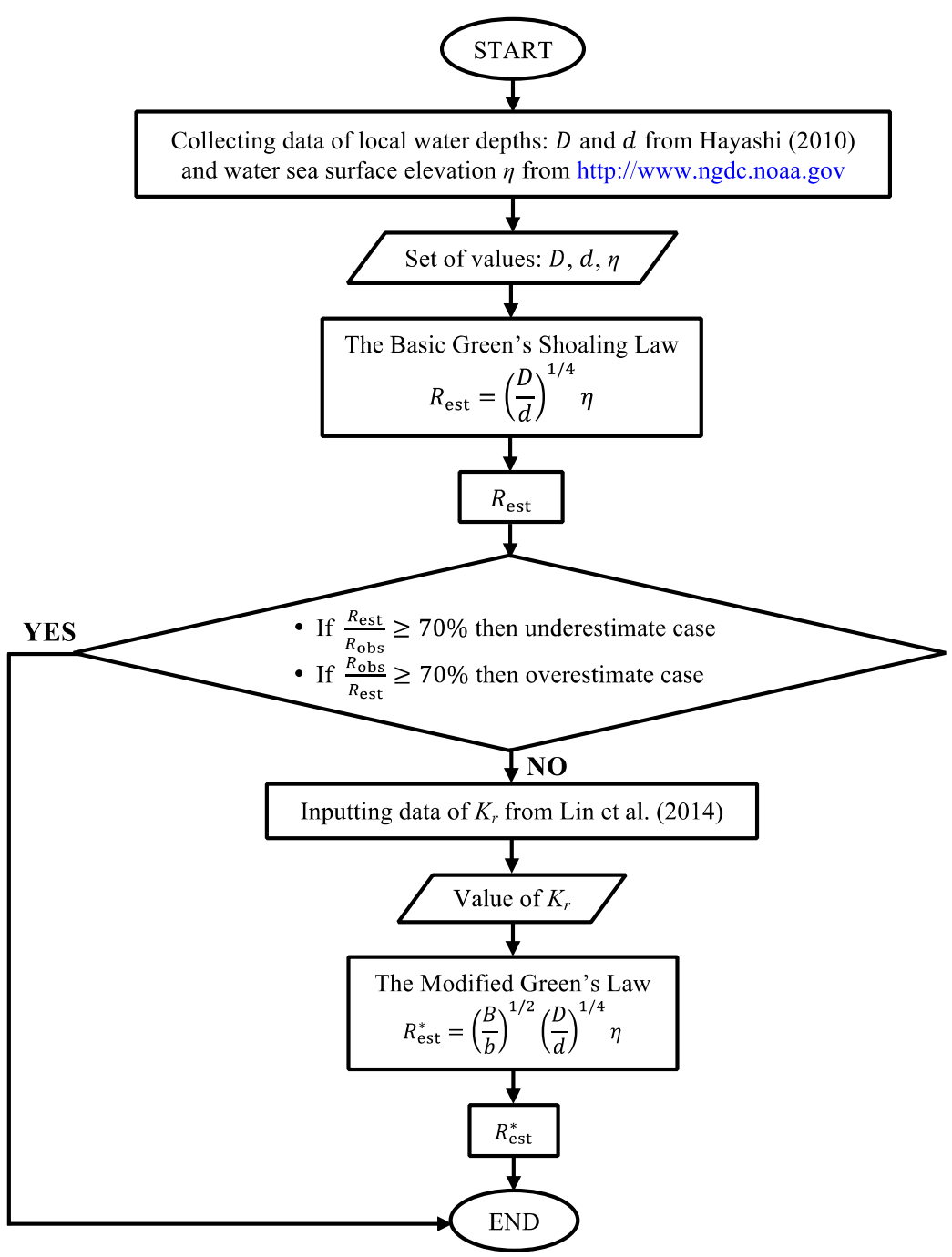

Figure 1. Simple flowchart, showing steps at calculating tsunami run-up height using the basic Green's shoaling law and its modified form considering both shoaling and refraction.

It should be noted that Eq. (2) is derived from the conservation of tsunami energy density by excluding the effect of wave refraction when the wave approaches a coastline. However, from a theoretical point of view the reduced speed will not only cause an increase in the wave height on a beach but also a change in the direction of wave propagation, particularly when wave rays are incident at an angle with respect to the normal direction of the assumed straight coastline. Adopting the geometry of wave propagation along different paths of wave rays, widely known as the Snell's law, and still in the absence of dissipation, we take into account for ray separation of two adjacent ray paths to reformulate the basic Green's law given in Eq. (2), resulting in

$$
R_{\mathrm{est}}^{*}=\left(\frac{B}{b}\right)^{1 / 2}\left(\frac{D}{d}\right)^{1 / 4} \eta
$$

where $R_{\text {est }}^{*}$ is the maximum run-up height estimate owing to shoaling and refraction effects, and $B$ and $b$ are the spacing widths of two adjacent refracted wave rays at offshore and onshore, respectively. Eq. (3) confirms another cause for the increased wave height on a beach, that is, refraction. Thus, in this study effects of shoaling and refraction are considered to induce run-ups. The inclusion of these effects in the run-up parameterization can thus be written as

$$
R_{\mathrm{est}}^{*}=K_{r} K_{s} \eta \text {, }
$$


where $K_{r}=\left(\frac{B}{b}\right)^{1 / 2}$ and $K_{S}=\left(\frac{D}{d}\right)^{1 / 4}$ are coefficients of refraction and shoaling, respectively. The whole steps in tsunami run-up prediction using the local water depths and the spacing widths induced by wave behavior can be examined in Figure 1.

\section{Results and Discussion}

We here provide two cases of large tsunamis that occurred in the Japanese east coast and another large tsunami event that severely hit the north-west coast of Sumatra island, from which the data available in this study were drawn and used to test the run-up estimate given by Eq. (2). The calculated results are hereby compared to field data from observational studies available at http://www.ngdc.noaa.gov and direct surveys (Mori et al., 2011; Goto et al., 2013), and also to relevant data developed from numerical codes (Hirata et al., 2004; Lin et al., 2014). Detailed data and the calculated run-ups $R_{\text {est }}$ using Eq. (2) in this study as well as the relevant corresponding observed values $R_{\text {obs }}$ are listed in Table 1 below.

Table 1. A list of tsunami run-up heights derived from theoretical prediction $R_{\text {est }}$ using the Green's law given by Eq. (2) and the corresponding measured values $R_{\text {obs }}$ of the run-ups obtained from field observations of large tsunami events.

\begin{tabular}{|c|c|c|c|c|c|c|c|c|c|c|}
\hline \multirow{2}{*}{$\begin{array}{l}\text { Tsunami } \\
\text { event }\end{array}$} & \multirow{2}{*}{$\begin{array}{c}D \\
(\mathrm{~m})\end{array}$} & \multirow{2}{*}{ Latitude } & \multirow{2}{*}{ Longitude } & \multirow{2}{*}{$\underset{(m)}{\eta}$} & \multirow{2}{*}{$\underset{(\mathrm{m})}{d}$} & \multirow{2}{*}{ Latitude } & \multirow{2}{*}{ Longitude } & \multicolumn{2}{|c|}{$R(\mathrm{~m})$} & \multirow{2}{*}{$\begin{array}{l}\text { The Green's } \\
\text { law in Eq. (2) }\end{array}$} \\
\hline & & & & & & & & $R_{\text {est }}$ & $R_{\text {obs }}$ & \\
\hline \multirow[t]{9}{*}{ Tohoku } & 53.0 & $39.00 \mathrm{~N}$ & $141.47 \mathrm{E}$ & 3.20 & 8.30 & $39.01 \mathrm{~N}$ & $141.45 \mathrm{E}$ & 5.09 & 24.00 & not applicable \\
\hline & 49.8 & $39.15 \mathrm{~N}$ & $141.56 \mathrm{E}$ & 4.10 & 5.40 & $39.16 \mathrm{~N}$ & $141.53 \mathrm{E}$ & 7.14 & 9.00 & confirmed \\
\hline & 27.7 & $40.33 \mathrm{~N}$ & $141.34 \mathrm{E}$ & 2.70 & 9.90 & $40.32 \mathrm{~N}$ & $141.33 \mathrm{E}$ & 3.49 & 9.00 & not applicable \\
\hline & 125 & $40.12 \mathrm{~N}$ & $142.07 \mathrm{E}$ & 4.04 & 0.75 & $40.12 \mathrm{~N}$ & $141.89 \mathrm{E}$ & 14.70 & 18.51 & confirmed \\
\hline & 200 & $39.63 \mathrm{~N}$ & $142.19 \mathrm{E}$ & 6.15 & 0.63 & $39.63 \mathrm{~N}$ & $142.06 \mathrm{E}$ & 26.82 & 23.65 & confirmed \\
\hline & 204 & $39.26 \mathrm{~N}$ & $142.10 \mathrm{E}$ & 6.35 & 0.60 & $39.26 \mathrm{~N}$ & $141.95 \mathrm{E}$ & 27.31 & 8.92 & not applicable \\
\hline & 160 & $38.86 \mathrm{~N}$ & $141.89 \mathrm{E}$ & 5.58 & 0.07 & $38.86 \mathrm{~N}$ & $141.72 \mathrm{E}$ & 37.26 & 12.57 & not applicable \\
\hline & 144 & $38.23 \mathrm{~N}$ & $141.68 \mathrm{E}$ & 5.77 & 0.27 & $38.23 \mathrm{~N}$ & $141.14 \mathrm{E}$ & 26.18 & 2.16 & not applicable \\
\hline & 137 & $36.97 \mathrm{~N}$ & 141.18 E & 2.60 & 1.41 & $36.97 \mathrm{~N}$ & $141.00 \mathrm{E}$ & 7.85 & 5.00 & not applicable \\
\hline \multirow[t]{3}{*}{ Tokachi } & 50.1 & $42.54 \mathrm{~N}$ & $144.23 \mathrm{E}$ & 0.98 & 3.80 & $42.58 \mathrm{~N}$ & $144.22 \mathrm{E}$ & 1.87 & 1.20 & not applicable \\
\hline & 53.0 & $39.00 \mathrm{~N}$ & $141.47 \mathrm{E}$ & 0.22 & 7.20 & $39.01 \mathrm{~N}$ & $141.45 \mathrm{E}$ & 0.36 & 0.28 & confirmed \\
\hline & 27.7 & $40.33 \mathrm{~N}$ & $141.34 \mathrm{E}$ & 0.63 & 3.20 & $40.32 \mathrm{~N}$ & $141.33 \mathrm{E}$ & 1.08 & 0.67 & not applicable \\
\hline \multirow[t]{3}{*}{ Aceh } & 50 & $6.8 \mathrm{~N}$ & $82.00 \mathrm{E}$ & 3.00 & 0.32 & $6.8 \mathrm{~N}$ & $81.80 \mathrm{E}$ & 10.61 & 6.97 & not applicable \\
\hline & 50 & $7.4 \mathrm{~N}$ & $81.93 \mathrm{E}$ & 3.33 & 0.32 & $7.4 \mathrm{~N}$ & $81.83 \mathrm{E}$ & 11.77 & 5.31 & not applicable \\
\hline & 50 & $7.2 \mathrm{~N}$ & $81.90 \mathrm{E}$ & 3.70 & 0.32 & $7.2 \mathrm{~N}$ & $81.85 \mathrm{E}$ & 13.08 & 4.97 & not applicable \\
\hline
\end{tabular}

It can be clearly seen from Table 1 that some values of calculated run-ups $R_{\text {est }}$ using Eq. (2) fall smaller than the corresponding observed values $R_{\mathrm{obs}}$ and others are greater than $R_{\mathrm{obs}}$ values. The former is classified into 'underestimate case' where $R_{\text {est }}<R_{\text {obs }}$ whereas the latter is grouped into 'overestimate case' where $R_{\text {est }}>R_{\mathrm{obs}}$. It is obvious from Table 1 that only 4 observational points (3 points from the Tohoku and another point from the Tokachi) among a total of 15 points of observations listed confirmed the basic Green's law written in Eq. (2), where $R_{\text {est }}$ is equal to or greater than $70 \%$ of $R_{\mathrm{obs}}$ for the case of underestimate prediction and $R_{\mathrm{obs}}$ is equal to or greater than $70 \%$ of $R_{\text {est }}$ for the case of overestimate prediction, similar to concluding remarks in terms of the difference between computed and measured values of the run-up height (Hayashi, 2010). However, 11 of 15 observational points (of about 73\%), indicate failures of the basic Green's law in 
predicting the maximum run-up height (written as 'not applicable' in the listed data of Table 1). This fact tells us that refraction among all wave phenomena occurring at and nearby a shoreline is the main candidate responsible for inaccuracy in the run-up prediction.

Regarding unsatisfactory results, i.e. the Green's shoaling law of tsunami run-up height prediction by Eq. (2) fails to calculate run-up height accurately, we need to recalculate all run-up values by incorporating refraction effect into the basic form of the Green's law in Eq. (2) and see if the new calculated results $R_{\text {est }}^{*}$ are better values in that they are closer to the observed run-up heights. This argument is relatively easy to understand in the sense that the effect of refraction is the cause for convergence in a cape where tsunami energy is focused and divergence on a bay where the energy is distributed over a larger area. Using Eq. (3) as the modified Green's law where two factors: shoaling and refraction are both considered, we again provide run-up height estimates. As both the convergence and divergence mechanisms require spacing widths of two wave rays that are normal to the corresponding wave fronts, Eq. (3) requires $B$ and $b$ be written in separate values that are difficult to obtain in field measurements in the open ocean. Therefore, we write here $\frac{B}{b}$ as the aspect ratio of wave ray spatial-separation due to refraction induced by the nature of wave behavior and rewrite Eq. (3) as Eq. (4) where all the new results are now listed in Table 2. However, we do not have reliable data for some observational points, leaving them uncorrected, as seen in the Tohoku lines 4 and 5.

Table 2. Run-up heights predicted by the basic Green's law $R_{\text {est }}$ in Eq. (2) and the modified Green's law $R_{\text {est }}^{*}$ in Eq. (4) and the corresponding measured values $R_{\mathrm{obs}}$ of the run-ups obtained from field observations of large tsunami events.

\begin{tabular}{|c|c|c|c|c|c|c|c|c|c|}
\hline \multirow{2}{*}{$\begin{array}{l}\text { Tsunami } \\
\text { event }\end{array}$} & \multirow{2}{*}{$\begin{array}{c}D \\
(\mathrm{~m})\end{array}$} & \multirow{2}{*}{$\underset{(\mathrm{m})}{d}$} & \multirow{2}{*}{$K_{s}$} & \multirow{2}{*}{$K_{r}$} & \multirow{2}{*}{$\begin{array}{c}\eta \\
(\mathrm{m})\end{array}$} & \multicolumn{2}{|c|}{$R(\mathrm{~m})$} & \multirow{2}{*}{$\begin{array}{l}\text { The Green's law } \\
\text { in Eq. (2) }\end{array}$} & \multirow{2}{*}{$\begin{array}{c}\text { The modified Green's } \\
\text { law in Eq. (4) }\end{array}$} \\
\hline & & & & & & $R_{\text {est }}$ & $R_{\mathrm{obs}}$ & & \\
\hline \multirow[t]{9}{*}{ Tohoku } & 53.0 & 8.30 & 1.59 & 4.01 & 3.20 & 20.4 & 24.00 & not applicable & confirmed \\
\hline & 49.8 & 5.40 & 1.74 & 1.07 & 4.10 & 7.65 & 9.00 & confirmed & confirmed \\
\hline & 27.7 & 9.90 & 1.29 & 2.19 & 2.70 & 7.65 & 9.00 & not applicable & confirmed \\
\hline & 125 & 0.75 & 3.59 & - & 4.04 & - & 18.51 & confirmed & failure \\
\hline & 200 & 0.63 & 4.22 & - & 6.15 & - & 23.65 & confirmed & failure \\
\hline & 204 & 0.60 & 4.29 & 0.37 & 6.35 & 10.14 & 8.92 & not applicable & confirmed \\
\hline & 160 & 0.07 & 6.84 & - & 5.58 & - & 12.57 & not applicable & failure \\
\hline & 144 & 0.27 & 4.80 & - & 5.77 & - & 2.16 & not applicable & failure \\
\hline & 137 & 1.41 & 3.14 & 0.60 & 2.60 & 4.73 & 5.00 & not applicable & confirmed \\
\hline \multirow[t]{3}{*}{ Tokachi } & 50.1 & 3.80 & 1.91 & 0.76 & 0.98 & 1.41 & 1.20 & not applicable & confirmed \\
\hline & 53.0 & 7.20 & 1.65 & 0.88 & 0.22 & 0.32 & 0.28 & confirmed & confirmed \\
\hline & 27.7 & 3.20 & 1.72 & 0.73 & 0.63 & 0.79 & 0.67 & not applicable & confirmed \\
\hline \multirow[t]{3}{*}{ Aceh } & 50 & 0.32 & 3.54 & - & 3.00 & - & 6.97 & not applicable & failure \\
\hline & 50 & 0.32 & 3.54 & 0.40 & 3.70 & 5.20 & 4.97 & not applicable & confirmed \\
\hline & 50 & 0.32 & 3.54 & 0.50 & 3.33 & 5.88 & 5.31 & not applicable & confirmed \\
\hline
\end{tabular}

In the process of examining the modified Green's law by both Eqs. (3) and (4), we also found $K_{r}$ to be difficult to determine. Hence, we say 'failure' in the last column of Table 2 for points with no values of $K_{r}$ (note that the failures may relate to confirmed estimates on the basis of shoaling only or to points where the shoaling prediction is not applicable). The new results clearly confirm 10 of 15 observational points, which is about $67 \%$, with all confirmed datasets having values of $R_{\text {est }}^{*}$ closer 
to the existing run-ups $R_{\mathrm{obs}}$. In other words, this shows an increase in the number of observational points, from 4 to 10 points with a reasonable accuracy, in which case the modified Green's law is applicable for run-up height prediction (points confirmed are those having $R_{\text {est }} \geq 0.85 R_{\text {obs }}$ for underestimate cases and $R_{\text {est }} \leq 0.85 R_{\text {obs }}$ for overestimate cases). Therefore, as suggested by previous work (WMO, 1998; Fuchs, 2013), the inclusion of refraction is compulsory in tsunami runup prediction as it seems to resolve the problem.

We also notice in the last column of Table 2 that some points of observations are failures. We here provide further clarification using the fact that complicated processes involved during tsunami wave propagation from a source location at an open sea to places offshore and onshore. While in this study the two combined effects of shoaling and refraction are considered, there are phenomena associated with wave behavior that play a role in run-ups are not yet incorporated, including effects of reflection and dispersion, and energy dissipation. Other external parameters, such as the geometry of the coast, coastal topography, and nearshore bathymetry may influence run-up parameterization, as claimed by some previous work on run-up and inundation estimation (Hayashi, 2010; Mori et al., 2011; Chen et al., 2012; Goto et al., 2013; Lin et al., 2014). For now, this study does not consider these effects as it concerns only on a simple parameterization for tsunami run-up prediction and therefore the incorporation of more local effects into the run-up estimate is challenging for future work.

\section{Conclusion and Remarks}

The basic Green's shoaling law with only parameters of local water depths for prediction of an inland tsunami run-up height seems to oversimplifying factors originating from dynamics of shoreward tsunami wave propagation that may influence on the maximum run-up. The Green's shoaling prediction, however, can be used to the first order to estimate the run-up with caution in the sense that non-linearity of the governing equations describing the dynamics of a tsunami as it approaches on a beach and complexities, such as local bathymetry and coastal topography are not yet included in the prediction. Refraction effect, the one among these factors, is found to be the cause for the deviation of run-up measurements from the basic Green's law. In the context of hazard mitigation study developed in Indonesia, the results reported from the present work aims to increasing awareness, to a maximum point for minimizing disaster risks, of the vulnerability of living communities and local infrastructures at and nearby the shorelines. The final goal in terms of downstream research is to do disaster prevention by educating people living in coastal areas that are vulnerable to geophysical hazards to be well aware of what a possible disaster to come and how to respond to the disaster. Therefore, the best efforts made for tsunami run-up height prediction should not underestimate the possible factors and that the use of the best expertise to counteract these natural forces is on demand for future work.

\section{Acknowledgment}

The authors would gratefully like to thank anonymous reviewer(s) of the 2017 IConSSE for valuable comments upon the paper. Along with discussion during the conference parallel session, all suggested comments are appreciated for clarity and completeness of the paper required for publication in The Journal of Science and Science Education (JoSSE). 


\section{References}

Choi, B. H., Kaistrenko, V., Kim, K. O., Min, B. I., \& Pelinovsky, E. (2011). Rapid forecasting of tsunami runup heights from 2-D numerical simulations. Natural Hazards and Earth System Science, 11, 707-714.

Synolakis, C. E. (1991). Green's law and the evolution of solitary waves. Physics of Fluids, 3, 490-491.

Mori, N., Takahashi, T., Yasuda, T., \& Yanagisawa, H. (2011). Survey of 2011 Tohoku earthquake tsunami inundation and run-up. Geophysical Research Letters, 38, L00G14.

Reymond, D., Okal, E. A., Hebert, H., \& Bourdet, M. (2012). Rapid forecast of tsunami wave heights from a database of pre-computed simulations, and application during the 2011 Tohoku tsunami in French Polynesia. Geophysical Research Letters, 39, 1-6.

Goto, K., Fujima, K., Sugawara, D., Fujino, S., Imai, K., Tsudaka, R., Abe, T., \& Haraguchi, T. (2013). Field measurements and numerical modeling for the run-up heights and inundation distances of the 2011 Tohoku-oki tsunami at Sendai plain, Japan. Earth, Planets Space, 64, 1247-1257.

Charvet, I., Eames, I., \& Rossetto, T. (2013). New tsunami runup relationships based on long wave experiments. Ocean Modelling, 69, 79-92.

Chen, G. Y., Lin, C. H., \& Liu, C. C. (2012). Quick evaluation of runup height and inundation area for early warning of tsunami. Journal of Earthquake and Tsunami, 6, 1250005-1-1250005-2.

Lin, J. H., Cheng, C. Y., Yu, J. L., Chen, Y. Y., \& Chen, G. Y. (2014). Quick estimation of tsunami induced run-up on coastal area. Paper presented at The $34^{\text {th }}$ Conference on Coastal Engineering, Seoul, South Korea. ISBN: 978-0-9896611-2-6.

WMO. (1998). Guide to wave analysis and forecasting (2nd ed.). Secretariat of the World Meteorological Organization (WMO)-702, Geneva, Switzerland, 58 \& 81-82.

Hayashi, Y. (2010). Empirical relationship of tsunami height between offshore and coastal stations. Earth, Planets Space, 62, 269-275.

Fuchs, H. (2013). Solitary impulse wave run-up and overland flow (Unpublished doctoral dissertation). The Swiss Federal Institute of Technology (ETH), Zurich.

Hirata, K., Tanioka, Y., Satake, K., Yamaki, S., \& Geist, E. L. (2004). The tsunami source area of the 2003 Tokachi-oki earthquake estimated from tsunami travel times and its relationship to the 1952 Tokachioki earthquake. Earth, Planets Space, 56, 367-372.

The US Government, National Geophysical Data Center (NGDC), National Oceanic and Atmospheric Administration (NOAA). (2017). Retrieved from http://www.ngdc.noaa.gov. 